\title{
AVALIAÇÃO DE STAPHYLOCOCCUS AUREUS EM ALIMENTOS COMERCIALIZADOS NO MUNICÍPIO DE DIVINÓPOLIS, MINAS GERAIS
}

\author{
SOUZA, R. O. ${ }^{1}$; CRUZ, L, F. ${ }^{1}$; COELHO, M. B. ${ }^{1}$; SOARES, L. A. ${ }^{1}$; \\ GOMES, A. A. ${ }^{2}$; SOARES, J. O. ${ }^{2}$; OLIVEIRA, L. F.3; MAGALHÃES, J. T. ${ }^{3}$ \\ ${ }^{I}$ Alunos de graduação da Universidade Federal de São João del-Rei, Campus CCO \\ ${ }_{2}^{2}$ Auditoras da Secretaria Municipal de Saúde/Divinópolis/MG \\ ${ }^{3}$ Professores da Universidade Federal de São João del-Rei, Campus CCO \\ *ramonsouza8@hotmail.com
}

\section{Resumo}

A alimentação é motivo de preocupação e nos últimos anos o número de pessoas que se alimentam fora de suas residências é cada vez maior, devido ao crescimento das cidades e ao pouco tempo disponível para o preparo das refeições, o que remete a procura pelos restaurantes self-service. Do ponto de vista de saúde pública os alimentos ofertados ao consumo humano devem ser de boa qualidade, dentro de padrões pré-estabelecidos, porém não só em valores nutritivos, mas também quanto às condições higiênicas adequadas. Dentre os diversos tipos de microrganismos patogênicos que podem ser transmitidos por alimentos destaca-se o Staphylococcus aureus, cuja importância epidemiológica está vinculada a graves intoxicações alimentares, devido as toxinas que formam durante o armazenamento inadequado dos alimentos. Assim, este trabalho teve como objetivo analisar a presença de $S$. aureus em alimentos comercializados em restaurantes centrais de Divinópolis, MG. Oitenta e sete alimentos coletados foram classificados e agrupados de acordo com sua preparação: Grupo A Saladas cruas; Grupo B - alimentos cozidos e Grupo C - alimentos multiingredientes. As análises foram realizadas pela técnica de contagem direta em meio seletivo Ágar Baird Parker e o teste de coagulase foi para confirmação das espécies coagulase positivas. Os resultados foram interpretados segundo a resolução 12 de 2001 da ANVISA. O grupo A apresentou 42\% dos alimentos acima dos valores estabelecidos pela legislação vigente, seguido pelo grupo B com $12 \%$ e grupo C com $22 \%$. Desta forma, os resultados indicam que alimentos crus apresentam maior contaminação devido ao fato de não passarem 
por um processamento térmico. Já os alimentos mistos apresentam tais resultados devido a falhas no processamento e armazenamento dos alimentos, já que a qualidade de uma refeição é influenciada por fatores como higiene dos utensílios, manipuladores e o monitoramento de parâmetros como tempo e temperatura.

Palavras-chave: Alimentos Seguro, Staphylococcus aureus

Apoio Financeiro: FAPEMIG, CNPq, UFSJ 